highly on the FFT. Working in partnership with local charitable organisations underpins working with difficult to reach groups.

\section{P106 ENSURING STAFF TRAINING IN INTEGRATED GUM SERVICES IN TRANSGENDER HEALTH ISSUES IS IMPORTANT: SEXUAL HEALTHCARE PROFESSIONALS (HCP) WANT SMALL GROUP TEACHING}

${ }^{1}$ Bethan Machado*, ${ }^{1,2}$ Kate Nambiar, ${ }^{1,2}$ Daniel Richardson. ${ }^{1}$ Brighton and Sussex Medical School, Brighton, UK; ${ }^{2}$ Brighton and Sussex University Hospitals NHS Trust, Brighton, UK

\subsection{6/sextrans-2016-052718.160}

Background/introduction Locally there is a large transgender (trans) population. As part of a health inequalities initiative in 2012 a bespoke sexual health service for trans patients (Clinic-T) was set up. This included HCP training.

Aim(s)/objectives To evaluate the current service relating to care and management of trans patients within the Claude Nicol Centre.

Methods Online survey - emailed to all staff between February and March 2016.

Results 45 HCP completed the survey. Job roles were: Doctor 21/45 (47\%), Nurse 17/45 (38\%), Health Advisor 3/45 (7\%), HCA 1/45 (2\%), Admin/Reception staff 3/45 (7\%). 31/45 (69\%) of the respondents had been working in sexual health for at least 6 years. The majority of respondents, 36/44 (82\%), do not see patients during Clinic-T. However, 16/45 (36\%) see trans patients at least three monthly and 29/45 (64\%) see trans patients less frequently than every 6 months. 33/43 (77\%) of HCP did not feel confident about seeing trans patients in a clinical setting - specific aspects include: 21/42 (50\%) understanding sexual health needs, 35/43 (81\%) where to seek gender reassignment advice, 40/43 (93\%) seeking hormonal replacement therapy advice, 32/43 (74\%) addressing psychological issues, and 34/ $43(79 \%)$ providing additional support in the community. The majority of HCP 26/45 (58\%) would like further training to be delivered through small group teaching.

Discussion/conclusion The majority of HCP are not confident when approaching trans patients at work. With a significant number of HCP seeing trans patients in general clinics it is important to ensure that broader sexual health services are acceptable to the local trans population. Programmes of education are needed to underpin quality improvement.

\section{P107 IDENTIFYING ABUSE IN SEXUAL HEALTH SETTINGS - HOW WELL ARE WE DOING?}

Arnold Fernandes*, Alison Squibb, Joanna Fitzgerald, Alison Brazington, Kate Horn. Royal United Hospital, Bath, UK

\section{$10.1136 /$ sextrans-2016-052718.161}

Background/introduction There is increasing evidence to suggest that individuals, who have encountered abuse of any nature, may present in a variety of health care settings and with a multiplicity of symptoms without disclosing the fact that the underlying reason for their presentation is abuse. In 2015 we introduced a prompt in our template to encourage professionals to raise the issue of abuse with all attendees to our unit.

Aim(s)/objectives Our aim was to assess how often abuse was disclosed, identify the nature of the abuse and offer support when this was requested.
Methods Retrospective review of all attendees to the Walk-in sessions over the course of a month in February 2016. A total of 106 notes were reviewed.

Results Of the 106 attendees interviewed, 8 (13.25\%) reported abuse. Of these, 6 were women and 2 were men. In all cases the abuse was disclosed, only on direct questioning. All 8 cases reported historical abuse. Physical and emotional abuse, were commonly reported. 3 of the women were aged between 21-30 years and 2 between 51-60 years. The men were aged 21 and 41. All attendees were offered the option of referral for further support, but all declined as all felt that they had either received support previously or had the opportunity to get over the trauma of what they had encountered.

Discussion/conclusion This audit demonstrates that abuse is common among attendees to Sexual health. This may not be disclosed unless raised as a matter of routine.

\section{P108 CAN INTEGRATED SEXUAL HEALTH SERVICES FUNCTION EFFECTIVELY WITHOUT A HEALTH ADVISOR?}

Jennifer McCay. Bridgewater NHS Trust, Trafford, Uganda

10.1136/sextrans-2016-052718.162

Background/introduction Four services merged to create one integrated sexual health service. The service is operating without a health advisor. Basic health advising duties are carried out by nursing staff.

Aim(s)/objectives Assess the effectiveness of current practice in relation to adherence to BASHH PN standards and consider changing practice and/or service provision if adherence is found to be poor.

Methods The inclusion criteria is any patients attending the service 01/08/2015-30/09/2015 who had a C4 diagnosis. The notes were reviewed retrospectively and the level of PN was checked against BASHH standards.

Results 90 patients were in the sample. 96\% of patients had PN discussed at the time of treatment. 57\% had PN agreed for each contact and PN outcomes documented, 0.66 contacts per index patient were reported as attended, 0.3 contacts per index patient were verified at attended, $79 \%$ of patients had a follow-up compliance check.

Discussion/conclusion Adherence to BASHH PN standards was better than expected. Measures were taken to improve adherence including prompts on the new EPR system to initiate and review PN. The recalls policy was updated and a compliance check proforma was introduced. The audit demonstrated the need for a health advisor within an integrated sexual health service. Recruitment of a new health advisor for the service has commenced.

\section{P109 THE SANTÉ PROJECT: ATTITUDE TOWARDS STI RISK ASSESSMENT, PREFERENCES FOR STI BEHAVIOURAL RISK REDUCTION INTERVENTIONS: SERVICE USERS PERSPECTIVES}

\footnotetext{
${ }^{1}$ Anupama Roy*, ${ }^{2}$ Carina King, ${ }^{3}$ Alec Miners, ${ }^{1}$ Carrie Llewellyn, ${ }^{1}$ Alex Pollard, ${ }^{2}$ Richard Gilson, ${ }^{1,4}$ Daniel Richardson, ${ }^{4}$ Laura Clark, ${ }^{2}$ Fiona Burns, ${ }^{2}$ Alison Rodgers, ${ }^{2} J u l i a$ Bailey, ${ }^{2}$ Maryam Shahmanesh. 'Division of Primary Care and Public Health, Brighton and Sussex Medical School, Brighton, East Sussex, UK; ${ }^{2}$ Research Department of Infection and Population Health, University College London, London, UK; ${ }^{3}$ Department of Health Services, London School of Hygiene and Tropical Medicine, London, UK; ${ }^{4}$ Brighton and Sussex University Hospital NHS Trust, brighton, East Sussex, UK
}

10.1136/sextrans-2016-052718.163 
Background/introduction A variety of risk-reduction interventions may be suitable for sexual health clinic attendees.

Aim(s)/objectives In the SANTE project, we explored service users' (SU) perceptions of their STI risk, and experiences and preferences for risk reduction interventions.

Methods Semi-structured interviews were conducted with 15 young people (YP) (16-25 years) and 20 MSM ( $\geq 16$ years) from two SH clinics. Data were analysed thematically. Based on these, a Discrete Choice Experiment (DCE) to quantitatively assess YP and MSM preferences for interventions was designed and conducted in three clinics $(\mathrm{n}=371)$.

Results Most participants, despite presenting with symptoms or concerned about STIs, did not perceive themselves to be at risk. Most reported receiving $\mathrm{SH}$ promotion but felt access to accurate information was lacking. While short advert-like videos were acceptable, onscreen material in waiting rooms was deemed inappropriate by some SUs. Opinions on group sessions were mixed. 1:1 sessions were favoured, with talking therapies acceptable if needed. Privacy around mobile apps was a concern while online materials from a reputable source were acceptable. DCE results demonstrated preferences for 'talking interventions', while all interventions were generally preferred to 'nothing'. People strongly disliked peer-led interventions compared to others, and preferred 1:1 to group sessions. Latent class analysis identified three respondent groups, those that preferred talking (56\%), email/text (29\%) or nothing (15\%).

Discussion/conclusion Young people and MSM welcome SH promotion offered through $\mathrm{SH}$ clinics. Triangulation demonstrated strong preferences for 1:1 talking interventions. Awareness of sexual risk was not commensurate with actual risk, suggesting that providers need to direct service users to appropriate interventions.

\section{P110 THE SANTÉ PROJECT: A MIXED-METHODS ASSESSMENT OF OPPORTUNITIES AND CHALLENGES FOR THE DELIVERY OF BRIEF RISK REDUCTION INTERVENTIONS IN SEXUAL HEALTH CLINICS IN ENGLAND - A HEALTHCARE PROVIDER'S PERSPECTIVE}

${ }^{1}$ Carina King*, ${ }^{2}$ Anupama Roy, ${ }^{1}$ Maryam Shahmanesh, ${ }^{1}$ Richard Gilson, ${ }^{2,3}$ Daniel Richardson, ${ }^{1}$ Fiona Burns, ${ }^{1}$ Alison Rodgers, ${ }^{1}$ Nicholas Massie, ${ }^{1} J u l i a$ Bailey, ${ }^{2}$ Carrie Llewellyn. ${ }^{1}$ Department of Infection and Population Health, University College London, London, UK; ${ }^{2}$ Division of Primary Care and Public Health, Brighton and Sussex Medical School, Brighton, East Sussex, UK; ${ }^{3}$ Brighton and Sussex University Trust, Brighton, East Sussex, UK

\subsection{6/sextrans-2016-052718.164}

Background/introduction Sante is a study to improve targeted sexual health promotion in UK sexual health $(\mathrm{SH})$ clinics.

Aim(s)/objectives We explored opportunities and challenges for delivering interventions including 1:1 and group sessions, digital and video interventions.

Methods Semi-structured interviews were conducted by telephone with healthcare providers (HCPs) from a range of clinics, by location, size, and patient mix. Data were analysed thematically using a framework approach. A web-survey was sent to key HCP contacts in SH services in England.

Results Interviews $(n=26)$ showed that digital interventions were viewed as logistically and financially feasible; some clinics reported already using them. All clinics provided brief 1:1 sessions, but challenges to delivery were identified as: lack of evidence for effectiveness on behaviours; costs and staff resourcing; and patient motivation. Videos received mixed opinions, they were seen as a practical option for providing STI information while patients wait, but issues about appropriateness were raised. HCPs had concerns about the feasibility of group sessions within clinic-based settings, while acknowledging their usefulness for outreach. The web-survey is ongoing; preliminary data indicates that clinics would like to be able to offer mobile apps, online education and videos (Table 1).

Discussion/conclusion Staff time, costs and logistics were universal challenges, while group sessions and videos raised issues of privacy in particular. Brief 1:1 interventions are currently widely delivered, and can be tailored to the patient's needs, but are resource-intensive while digital methods despite being uncommon were seen as desirable.

\begin{tabular}{|c|c|c|c|c|c|c|}
\hline & \multicolumn{3}{|c|}{ Level $3(n=36)$} & \multicolumn{3}{|c|}{ Level 2 ( $n=8)$} \\
\hline & \multirow{2}{*}{$\begin{array}{l}\text { Currently } \\
\text { offer }\end{array}$} & \multicolumn{2}{|c|}{ Currently not offered* } & \multirow{2}{*}{$\begin{array}{l}\text { Currently } \\
\text { offer }\end{array}$} & \multicolumn{2}{|c|}{ Currently not offered* } \\
\hline & & $\begin{array}{l}\text { Would } \\
\text { like }\end{array}$ & $\begin{array}{l}\text { Would not } \\
\text { like }\end{array}$ & & $\begin{array}{l}\text { Would } \\
\text { like }\end{array}$ & $\begin{array}{l}\text { Would not } \\
\text { like }\end{array}$ \\
\hline $\begin{array}{l}\text { Educational } \\
\text { videos }\end{array}$ & $0(0 \%)$ & $\begin{array}{l}19 \\
(53 \%)\end{array}$ & $9(25 \%)$ & $0(0 \%)$ & $4(50 \%)$ & $1(13 \%)$ \\
\hline $\begin{array}{l}\text { Online } \\
\text { education }\end{array}$ & $4(11 \%)$ & $\begin{array}{l}20 \\
(63 \%)\end{array}$ & $5(16 \%)$ & $4(50 \%)$ & $\begin{array}{l}4 \\
(100 \%)\end{array}$ & $0(0 \%)$ \\
\hline Mobile 'app' & $1(3 \%)$ & $\begin{array}{l}21 \\
(60 \%)\end{array}$ & $3(9 \%)$ & $0(0 \%)$ & $4(50 \%)$ & $0(0 \%)$ \\
\hline $\begin{array}{l}\text { Single 1:1 } \\
\text { sessions }\end{array}$ & $26(74 \%)$ & $4(40 \%)$ & $2(20 \%)$ & $6(75 \%)$ & $\begin{array}{l}2 \\
(100 \%)\end{array}$ & $0(0 \%)$ \\
\hline $\begin{array}{l}\text { Multiple 1:1 } \\
\text { sessions }\end{array}$ & $17(49 \%)$ & $9(47 \%)$ & $2(11 \%)$ & $3(38 \%)$ & $1(20 \%)$ & $1(20 \%)$ \\
\hline Group sessions & $3(9 \%)$ & $6(18 \%)$ & $18(55 \%)$ & $3(38 \%)$ & & $2(40 \%)$ \\
\hline
\end{tabular}

*Percentages are calculated based on the number of clinics not already providing this service. One clinic reported not providing any interventions.

\section{P111 PERCEPTIONS OF CHLAMYDIA SCREENING, CONTRACEPTION AND HIV TESTING AMONG 16-24 YEAR OLD PATIENTS VISITING A GP SURGERY}

${ }^{1}$ Leah Jones*, ${ }^{1}$ Ellie Ricketts, ${ }^{2}$ Katy Town, ${ }^{1}$ Donna Lecky, ${ }^{1}$ Claire Rugman, ${ }^{2}$ Kate Folkard, ${ }^{2}$ Anthony Nardone, ${ }^{2}$ Thomas Hartney, ${ }^{1}$ Cliodna McNulty. ${ }^{1}$ Primary Care Unit, Public Health England, Gloucester, UK; ${ }^{2}$ National Chlamydia Screening Programme, Public Health England, London, UK

\subsection{6/sextrans-2016-052718.165}

Background A complex intervention based on the Theory of Planned Behaviour significantly increased chlamydia screening in general practice (McNulty et al 2014). It may be more beneficial to extend this intervention to a broader sexual health offer including chlamydia testing, contraception advice and when appropriate, HIV testing (3Cs and HIV).

Aim To determine young adults' opinions of having a broader sexual health offer (3Cs and HIV) at their GP practice.

Methods Thirty interviews were conducted with 9 male and 21 female patients, 16-24 years in English GP practices. Participants were interviewed immediately before or after a routine practice attendance of any type. Data was analysed using a thematic framework and using QSR Nvivo 10.

Results Participants indicated that method of testing, timing and staff member approach were important aspects to chlamydia screening and contraception discussions. Participants displayed a clear preference for the GP practice over other sexual health 